\title{
Erratum to: How can straw incorporation management impact on soil carbon storage? A meta-analysis
}

\author{
Hong Zhao • Binfeng Sun • Ling Jiang • Fei Lu • \\ Xiaoke Wang • Zhiyun Ouyang
}

Published online: 11 June 2014

(C) Springer Science+Business Media Dordrecht 2014

\section{Erratum to: Mitig Adapt Strateg Glob Change \\ DOI 10.1007/s11027-014-9564-5}

The original version of this article unfortunately contained some mistakes. The co-authors, Hong Zhao, Binfeng Sun, Ling Jiang, Xiaoke Wang and Zhiyun Ouyang and their affiliations were omitted in the original version. The correct author group are shown above and their affiliations are given below.

The online version of the original article can be found at: http://dx.doi.org/10.1007/s11027-014-9564-5.

H. Zhao $\cdot$ B. Sun $\cdot$ L. Jiang $\cdot$ F. Lu $(\bowtie) \cdot$ X. Wang $\cdot$ Z. Ouyang

State Key Laboratory of Urban and Regional Ecology, Reasearch Center for Eco-Environmenal Sciences, Chinese Academy of Sciences, Shuangqinglu 18, Beijing 100085, China e-mail: feilu@rcees.ac.cn

H. Zhao $\cdot$ B. Sun $\cdot$ L. Jiang

University of Chinese Academy of Sciences, Yuquanlu 19, Beijing 100049, China 